\title{
Impact of packaging shape and material on consumer expectations
}

\section{ABSTRACT}

Packaging appearance is important in evoking consumer impressions. No study has yet explored how two prominent packaging attributes, shape and material, affect the consumers' impressions and their expectations in the case of coffee products. Therefore, the objective of this study was to investigate whether the packaging shape has an impact on the taste intensity expected by the consumer, and whether packaging materials influence the expected coffee quality. In an online experiment, 115 participants evaluated different packaging samples. They rated the expected taste intensity for packaging samples that varied in shape complexity (i.e., cylindrical, roundedangular, hexagonal and multifaceted). They also rated the expected coffee quality for packaging samples that varied in material (i.e., plastic, aluminium, glass and metal). The results showed that the packaging with a higher degree of shape complexity was associated with a higher taste intensity. Furthermore, we found a negative effect of glass on the expectation of product quality. The findings could be applied in product packaging design which aims to match the expected and actual characteristics of the product.

\section{KEY WORDS}

Packaging, coffee, shape, material, expected taste, perceived quality

\author{
Suzana Poslon \\ Dorotea Kovačević \\ Maja Brozović \\ University of Zagreb, \\ Faculty of Graphic Arts, \\ Zagreb, Croatia \\ Corresponding author: \\ Dorotea Kovačević \\ e-mail:dorotea.kovacevic@grf.hr
}

First received: 8.2.2021.

Accepted: 5.5.2021.

\section{Introduction}

Packaging appearance is important because it is the only form of communication between the product and the buyer during the first purchase (Dadras, 2015). A well-designed combination of packaging attributes with certain visual elements can evoke emotional reactions from the consumers. The most prominent packaging attributes, which contribute to the packaging appearance at first glance, are shape and material.

Previous studies showed that consumers are sensitive to visual shapes on the packaging. For example, a study by Westerman et al (2013) demonstrated a greater tendency towards designs which use round elements on packaging labels in the case of vodka and water. According to Hassan, Lee \& Peng (2012), the packaging shape is one of the two attributes that influences a purchase decision the most. The shape of packaging varies according to purpose and product type. Sometimes, deviation of packaging form from existing packaging design in a product category may draw more attention from the consumers (Schoormans \& Robben, 1997). Packaging shape can make the product more attractive and help consumers predict the volume of the product and its monetary value. In the area of food products, it can also impact the perception of product taste. The taste sensation (i.e., sweet, salty, bitter, acidic) can be activated even without consuming the product. This is commonly done through the visual design of the packaging, such as pictorial content and colours, but it can also be achieved through packaging shape (Velasco et al., 2014). If the shape corresponds to the actual taste of the product, the compatibility effect is perceived through two modalities: vision and taste, resulting in consumer satisfaction. If the consumers' created sensory and hedonic expectations do not match the actual taste of the product, there is a greater possibility for the consumers' dissatisfaction with the product and a decreased likelihood of repurchase (Ares \& Deliza, 2010). 
Another attribute that significantly influences the consumers' perception of the packaging is the material. Several studies from the last decade demonstrated the impact of the material on the participants' reactions. Kobayashi \& Benassi (2015) reported on the importance of the shape of glass jars for the consumers' acceptance and purchase intention. Steenis at el (2017) found that the packaging material affects the perception of sustainability, but also the perception of taste and quality. Labbe Pineau \& Martin (2013) revealed that the visual, auditory and tactile sensory diversity of the packaging materials result in differences in the consumers' expectations. Ferreira (2019) manipulated both the texture of the packaging material as well as the product texture and demonstrated their impact on taste perception.

Altogether, previous packaging-oriented researches suggest that both the shape and the material can influence people's perception and their responses to packaging. Thus, the focus of our study was on these packaging characteristics and their impact on the consumers' expectations from the product.

\section{Problem statement}

The investigation of the association between shapes and different flavours was interesting to researchers (Turoman et al., 2018). The existing literature suggests that packaging shape can be one of the influential factors in forming peoples' impressions about product taste. Previous studies (Velasco et al., 2014; Velasco et al., 2016) confirm that there is a connection between the shape and the taste. They found a correlation between sweet taste and rounded forms. On the other hand, sour and bitter flavours were more correlated with angular and sharp forms. Spence \& Ngo (2012) reported on the connection between stringent forms and an increase of bitterness, as well as the association of dairy and mint tastes with rounded shapes. Rounded shapes were also investigated in the study by Wang et al (2017) which showed that a round-shaped product is expected to be sweeter and less bitter than an angular-shaped one.

While most of the previous research was focused on sweet food products, our study went further in the examination of taste expectations in relation to packaging shape, by focusing specifically on coffee taste. Although there was a significant research interest in this popular drink (Harith, Ting \& Zakaria, 2014; Van Loo et al., 2015; van Ooijen et al., 2017; Wever et al., 2010), none of the previous studies reported on the possible connections between the expected coffee taste intensity and the shape of its packaging. So, our first hypothesis was:

$\mathrm{H}_{1}$ : Packaging shape has an influence on the expected taste intensity of the coffee.
Besides the packaging shape, its material can also affect people's perception of the product (Ferreira, 2019; Kobayashi \& Benassi, 2015), especially its perceived quality (Steenis et al., 2017). Consumers' expectations about the product quality can be based on various aspects of the material, such as sustainability (Steenis et al., 2017; Vukoje et al., 2020), texture (Ferreira, 2019), transparency (Chandran, Batra \& Lawrence, 2009; Sabo et al., 2017) and coating (Cigula et al., 2020; Dolić, Pibernik \& Majnarić, 2014; Hudika et al., 2020; Pibernik et al., 2020). From a practical viewpoint, all of these aspects mostly arise from product type, its specifications and requirements for its protection. When it comes to coffee products, their expected quality was investigated in the area of ready-to-drink beverages (Wang \& Yu, 2016) and product packaging design (van Ooijen et al., 2017). However, consumers' expectations about coffee quality have not been examined in relation to variations of packaging material. Accordingly, our second hypothesis was:

$\mathrm{H}_{2}$ : Packaging material has an influence on the expected quality of the coffee.

\section{Methodology}

In order to test the hypotheses, we conducted an online survey which consisted of two main parts. The first part of the survey included four samples of the packaging that varied according to shape, from cylindrical to multifaceted. For the second part of the survey, we used four different samples of the packaging which varied according to material.

The survey was active from 28.4.2020. to 9.5.2020. It included 115 respondents and all of them were over 18 years old. Only those who claimed that they consume coffee at least once a month were included. The highest percentage of participants ranged from 18 to 50 years of age (95.7\%), while only 5 participants (4.3\%) were older than $50.57 .2 \%$ were women and $42.8 \%$ were men. $51.3 \%$ of participants claimed that they drink coffee several times a day, $28.7 \%$ drink coffee once a day, 15,4\% drink coffee several times a week and $4,6 \%$ drink coffee several times a month.

In line with previous studies which dealt with food packaging (Ares \& Deliza, 2010; Velasco et al., 2014), images of empty coffee packaging were used in our study. For the first part of the survey, the images of different glass coffee containers were presented to the participants. Figure 1 shows the containers. Their packaging shape varied in complexity, and they were classified into four main packaging shapes; cylindrical (A), rounded-angular (B), hexagonal (C) and multifaceted packaging (D). The packaging volume was $250 \mathrm{~g}$, all of them were transparent, with the same lid colour and on the same background. The participants were asked to rate the expected coffee 
taste intensity for each packaging shape. The ratings were recorded using a five-point Likert scale ranging from 1 (low intensity) to 5 (high intensity).

In the second part of the survey, we used images of different packaging that varied in materials, which resulted in four different packaging samples shown in Figure 2; a plastic bag $(E)$, aluminium packaging $(F)$, a glass container $(\mathrm{G})$ and a metal box $(\mathrm{H})$. All packaging samples were in a neutral colour and had the same volume of $250 \mathrm{~g}$. The participants were asked to rate the expected coffee quality for each packaging sample, using a five-point Likert scale ranging from 1 (low quality) to 5 (high quality).

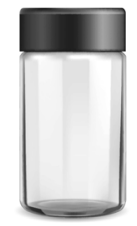

A

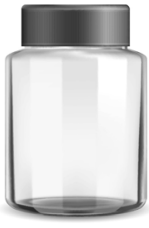

B

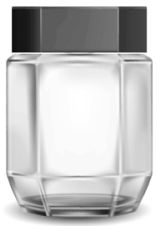

C

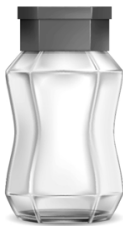

D
» Figure 1: Packaging samples used for the expected taste intensity

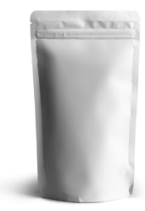

E

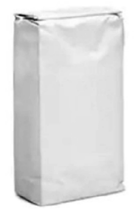

$\mathbf{F}$

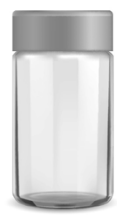

G

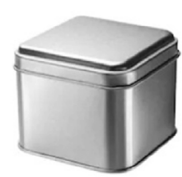

H
» Figure 2: Packaging samples used for the expected coffee quality

\section{Results}

In order to test our hypotheses, a repeated measures ANOVA was used. There was a significant effect of the packaging shape on the expected taste intensity,

$F(3,342)=12.30, p<0.05$. Post hoc tests were conducted with the Bonferroni correction (adjusted level of significance was set at $p<0.008)$. The results showed that the participants expected the same taste intensity of the coffee in the cylindrical and rounded-angular packaging, $p>0.008$. They also expected the same taste intensity of the coffee in the hexagonal and multifaceted packaging, $p>0.008$. However, the cylindrical packaging was associated with lower taste intensity ratings $(M=2.69$, $\mathrm{SD}=0.93)$ than the hexagonal packaging $(\mathrm{M}=3.21$, $S D=1.10), p<0.008$, and the multifaceted packaging $(M=3.22, S D=1.24), p<0.008$. Furthermore, the rounded-angular packaging was also associated with lower taste intensity ratings ( $\mathrm{M}=2.73, \mathrm{SD}=0.98)$ than the hexagonal packaging $(\mathrm{p}<0.008)$, and the multifaceted packaging, $p<0.008$. Figure 3 illustrates these results.
For the expected quality (see Fig. 4), the analysis showed that the packaging material affects the participants' expectations of the coffee quality $F(3,342)=13.52$, $p<0.05$. Post hoc tests were conducted with the Bonferroni correction and an adjusted level of significance $(p<0.008)$. There were no statistical differences in the expected quality between the coffee in the plastic bag, aluminium packaging and the metal box, all $p>0.008$. However, the quality was perceived as significantly lower for the glass container $(M=2.92, S D=0.93)$ than for the plastic bag $(M=3.55, S D=0.99, p<0.008)$, aluminium packaging $(\mathrm{M}=3.62, \mathrm{SD}=1.17, \mathrm{p}<0.008)$ and the metal box $(M=3.72, S D=1.26, p<0.008)$.

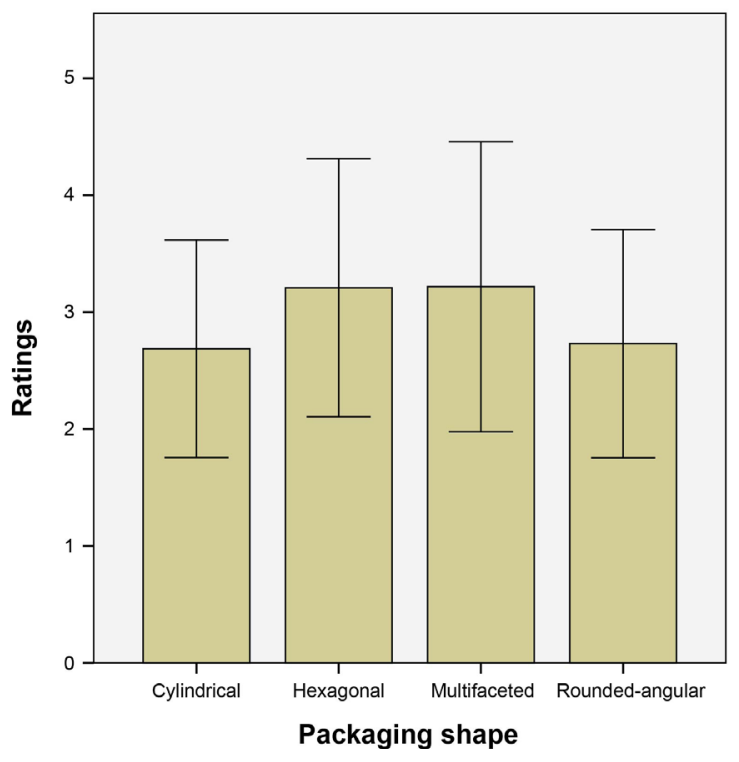

» Figure 3: Mean ratings and standard deviation for the expected taste intensity

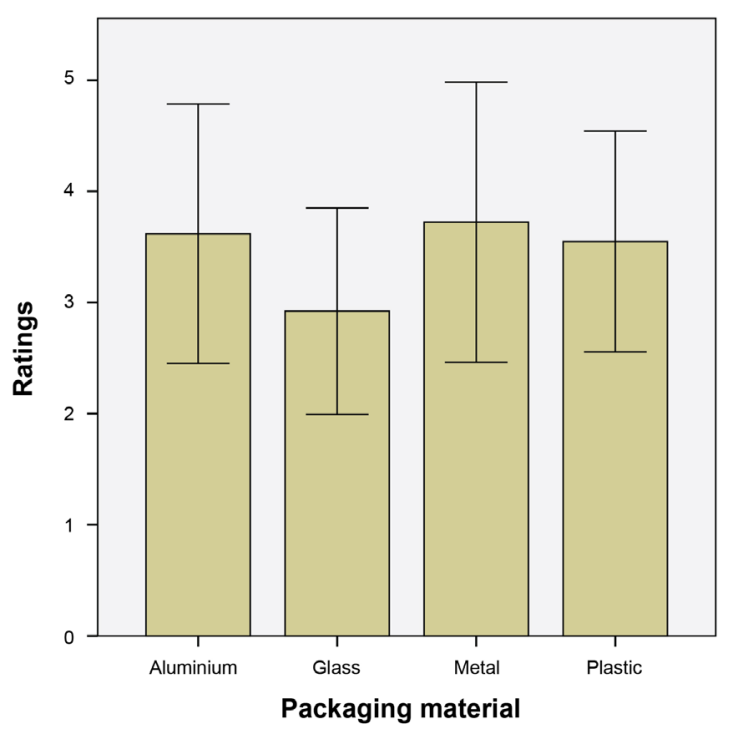

» Figure 4: Mean ratings and standard deviation for the expected quality 


\section{Discussion}

The results of our study confirmed both of our hypotheses. In particular, the packaging shape had an impact on the participants' ratings of the expected taste intensity, and the packaging material influenced their ratings of the expected coffee quality.

Becker et al (2011) have reported on the impact of packaging shape on the expected flavour in the case of yoghurt, and Heuvelmans's research (Heuvelmans, 2017) confirmed this in the case of chocolate. The results of our study confirmed it in the case of coffee as well. The participants perceived the cylindrical and the rounded-angular packaging as coffee with a lower taste intensity. However, the participants expected that more complex packaging shapes (i.e., the hexagonal and the multifaceted packaging) contained coffee with a high taste intensity. The connection between the angular shaped packaging and higher taste intensity is not surprising. Previous research showed that angular forms can affect the taste intensity in the case of yoghurt (Becker et al., 2011). Furthermore, Velasco et al (2016) confirmed that there is a correlation between bitter taste, which is the main flavour of coffee, and sharp forms. Similar results can also be found in recent research focused on coffee. Sousa, Carvalho \& Pereira (2020) investigated people's expectations of coffee acidity and sweetness in different packaging design conditions. They found that angular graphic elements printed on the packaging increased the expectations of acidity more than rounded elements. By connecting their results with those in our study, it is not unreasonable to expect that the combination of angular packaging with angular graphic elements printed on it may result in the consumers' predictive expectations of the coffee taste. However, this area should definitely be more investigated to provide researchbased evidence for this valuable design guideline.

When it comes to packaging material, our study demonstrated the negative effect of glass containers on the expected quality, since the glass container was rated significantly lower than the plastic bag, aluminium packaging and the metal box. Among all packaging samples in our study, the glass container was the only packaging made of a transparent material which enables light penetration. It is known that light can affect food and beverage quality (Duncan \& Hannah, 2012) and cause oxidation (Pristouri, Badeka \& Kontominas, 2010). Thus, it is likely that the participants associated the packaging material's light transmission with a decreased level of coffee aroma and quality. A study by Kobayashi and Benassi (2015) revealed similar results. The participants in their experiment were not keen on selecting glass coffee packaging unless it used modern forms that enable better visualization of the actual product. Our results confirm other previously reported scientific conclusions on consumer expectations of coffee quality.
For example, Harith et al (2014) reported that packaging can stimulate the perception of coffee quality. Fenko, de Vries \& van Rompay (2018) showed that packaging can guide the evaluation of the coffee product. Wang \& Yu (2016) demonstrated that packaging appearance can play a critical role in generating consumer perception of the product value. All these findings suggest that packaging design should not be underestimated in the process of transmitting the message about the product quality. The impact of different environmental aspects of people's experiences of drinking coffee should also be taken into consideration in this process (Spence \& Carvalho, 2020).

\section{Conclusions}

This study explored people's expectations of coffee in relation to its packaging attributes. The results revealed a significant effect of packaging shape on the expected taste intensity and the impact of packaging material on the consumers' perception of the coffee quality. The findings could be applied to future packaging design for certain types of coffee. Strong taste can be presented by increasing the level of packaging shape complexity. For example, cylindrical packaging can be used for mild coffee, while multifaceted packaging can be used for strong coffee. Consumers' expectations of low coffee quality can be avoided by using non-transparent packaging materials, such as metal box. Matching the expected and actual characteristics of the coffee product may create better trust between the consumer and the producer, which opens up possibilities for greater consumer satisfaction.

Since the online survey was conducted using two-dimensional photographs as stimuli, the study's main limitation is no physical contact between the participants and the realistic three-dimensional packaging samples. Viewing the samples in their actual structural form may, perhaps, evoke more noticeable effects on the participants' impressions and, consequently, their subjective expectations. Undoubtedly, despite the great scientific interest in packaging design, this area is still undeveloped and needs further research. Introducing a greater number of packaging variations for each material group could also provide useful insights. Future studies should also include coffee tasting tests which would provide wider research-based knowledge on the packaging's effects on the perception of taste in a realistic context.

\section{References}

Ares, G. \& Deliza, R. (2010) Studying the influence of package shape and colour on consumer expectations of milk desserts using word association and conjoint analysis. Food Quality and Preference. 21 (8), 930-937. Available from: doi: 10.1016/j.foodqual.2010.03.006 
Becker, L., van Rompay, T. J. L., Schifferstein, H. N. J. \& Galetzka, M. (2011) Tough package, strong taste: The influence of packaging design on taste impressions and product evaluations. Food Quality and Preference. 22 (1), 17-23. Available from: doi: 10.1016/j.foodqual.2010.06.007

Chandran, S., Batra, R. K. \& Lawrence, B. (2009) Is seeing believing? Consumer responses to opacity of product packaging. NA - Advances in Consumer Research. 36.

Cigula, T., Hudika, T., Katana, M., Golik Krizmanić, M. \& Tomašegović, T. (2020) The influence of PCL-ZnO coating composition on coated offset cardboard prints. In: Dedijer, S. (Ed.), Proceedings - The Tenth International Symposium GRID 2020, 12-14 November 2020, Novi Sad, Serbia. Novi Sad, Faculty of Technical Sciences, pp. 101-108. Available from: doi: 10.24867/grid-2020-p8

Dadras, A. (2015) Impact of shapes in packaging design on consumer behaviour in the lens of Kano's attractive quality theory. International Journal of Scientific Research and Management Studies. 2 (1), 78-86.

Dolić, J., Pibernik, J. \& Majnarić, I. (2014) Influence of UV varnish pattern effect on print quality. Journal of Imaging Science and Technology. 58 (6), 1-9. Available from: doi: 10.2352/J. ImagingSci.Technol.2014.58.6.060501

Duncan, S. E. \& Hannah, S. (2012) Light-protective packaging materials for foods and beverages. In: Kit, L. Y. \& Dong, S. L. (eds.) Emerging Food Packaging Technologies. Cambridge, United Kingdom, Woodhead Publishing, pp. 303-322. Available from: doi: 10.1533/9780857095664.3.303

Fenko, A., de Vries, R. \& van Rompay, T. (2018) How strong is your coffee? The influence of visual metaphors and textual claims on consumers' flavor perception and product evaluation. Frontiers in Psychology. 9, 1-12. Available from: doi: 10.3389/fpsyg.2018.00053

Ferreira, B. M. (2019) Packaging texture influences product taste and consumer satisfaction. Journal of Sensory Studies. 34 (6), 1-9. Available from: doi: 10.1111/joss.12532

Harith, Z. T., Ting, C. H. \& Zakaria, N. N. A. (2014) Coffee packaging: Consumer perception on appearance, branding and pricing. International Food Research Journal. 21 (3), 849-853.

Hassan, S. H., Lee, W. L. \& Peng, W. W. (2012) The influence of food product packaging attributes in purchase decision: A study among consumers in Penang, Malaysia. Journal of Agribusiness Marketing. 5, 14-28.

Heuvelmans, A. (2017) The influence of packaging shape on perceived taste for familiar and unfamiliar brands. MSc thesis. Faculteit der Letteren

Hudika, T., Tomašegović, T., Cigula, T. \& Prša, M. (2020) Polycaprolactone primers with zinc oxide and silicon dioxide nanoparticles for paper substrates: Influence on the properties of cyan and magen- ta offset prints. Coloration Technology. 136 (5), 435-449. Available from: doi: 10.1111/cote.12487 Kobayashi, M. L. \& Benassi, M. de T. (2015) Impact of packaging characteristics on consumer purchase intention: Instant coffee in refill packs and glass jars. Journal of Sensory Studies. 30 (3), 169-180. Available from: doi: 10.1111/joss.12142

Labbe, D., Pineau, N. \& Martin, N. (2013) Food expected naturalness: Impact of visual, tactile and auditory packaging material properties and role of perceptual interactions. Food Quality and Preference. 27 (2), 170-178. Available from: doi: 10.1016/j.foodqual.2012.06.009

Pibernik, J., Tomašegović, T., Mahović Poljaček, S. \& Madžar, A. (2020) Consumer's experience of tea packaging as environment-friendly. In: Dedijer, S. (Ed.), Proceedings - The Tenth International Symposium GRID 2020, 12-14 November 2020, Novi Sad, Serbia. Novi Sad, Faculty of Technical Sciences, pp. 317-325. Available from: doi: 10.24867/grid-2020-p35

Pristouri, G., Badeka, A. \& Kontominas, M. G. (2010) Effect of packaging material headspace, oxygen and light transmission, temperature and storage time on quality characteristics of extra virgin olive oil. Food Control. 21 (4), 412-418. Available from: doi: 10.1016/j.foodcont.2009.06.019

Sabo, B., Bečica, T., Keleš, N., Kovačević, D. \& Brozović, M. (2017) The impact of packaging transparency on product attractiveness. Journal of Graphic Engineering and Design. 8 (2), 5-9. Available from: doi: 10.24867/JGED-2017-2-005

Schoormans, J. P. L. \& Robben, H. S. J. (1997) The effect of new package design on product attention, categorization and evaluation. Journal of Economic Psychology. 18 (2-3), 271-287. Available from: doi: 10.1016/S0167-4870(97)00008-1

Sousa, M. M. M. D., Carvalho, F. M. \& Pereira, R. G. F. A. (2020) Colour and shape of design elements of the packaging labels influence consumer expectations and hedonic judgments of specialty coffee. Food Quality and Preference. 83, 103902. Available from: doi: 10.1016/j.foodqual.2020.103902

Spence, C. \& Carvalho, F. M. (2020) The coffee drinking experience: Product extrinsic (atmospheric) influences on taste and choice. Food Quality and Preference. 80, 103802. Available from: doi: 10.1016/j.foodqual.2019.103802

Spence, C. \& Ngo, M. K. (2012) Assessing the shape symbolism of the taste, flavour, and texture of foods and beverages. Flavour. 1 (1), 1-13. Available from: doi: 10.1186/2044-7248-1-12

Steenis, N. D., van Herpen, E., van der Lans, I. A., Ligthart, T. N. \& van Trijp, H. C. M. (2017) Consumer response to packaging design: The role of packaging materials and graphics in sustainability perceptions and product evaluations. Journal of Cleaner Production. 162, 286-298. Available from: doi: 10.1016/j.jclepro.2017.06.036 
Turoman, N., Velasco, C., Chen, Y. C., Huang, P. C. \& Spence, C. (2018) Symmetry and its role in the crossmodal correspondence between shape and taste. Attention, Perception, and Psychophysics. 80 (3), 738-751. Available from: doi: 10.3758/s13414-017-1463-x

Van Loo, E. J., Caputo, V., Nayga, R. M., Seo, H. S., Zhang, B. \& Verbeke, W. (2015) Sustainability labels on coffee: Consumer preferences, willingness-to-pay and visual attention to attributes. Ecological Economics. 118, 215-225. Available from: doi: 10.1016/j.ecolecon.2015.07.011

van Ooijen, I., Fransen, M. L., Verlegh, P. W. J. \& Smit, E. G. (2017) Packaging design as an implicit communicator: Effects on product quality inferences in the presence of explicit quality cues. Food Quality and Preference. 62, 71-79. Available from: doi: 10.1016/j.foodqual.2017.06.007

Velasco, C., Salgado-Montejo, A., Marmolejo-Ramos, F. \& Spence, C. (2014) Predictive packaging design: Tasting shapes, typefaces, names, and sounds. Food Quality and Preference. 34, 88-95. Available from: doi: 10.1016/j.foodqual.2013.12.005

Velasco, C., Woods, A. T., Petit, O., Cheok, A. D. \& Spence, C. (2016) Crossmodal correspondences between taste and shape, and their implications for product packaging: A review. Food Quality and Preference. 52, 17-26. Available from: doi: 10.1016/j.foodqual.2016.03.005

Vukoje, M., Bolanča Mirković, I., Bešlić, M. \& Petković, G. (2020) The influence of artificial aging on recyclability and mechanical stability of pharmaceutical packaging. In: Dedijer, S. (Ed.), Proceedings - The Tenth International Symposium GRID 2020, 12-14 November 2020, Novi Sad, Serbia. Novi Sad, Faculty of Technical Sciences, pp. 251-259. Available from: doi: 10.24867/GRID-2020-p27
Wang, E. S. T. \& Yu, J. R. (2016) Effect of product attribute beliefs of ready-to-drink coffee beverages on consumer-perceived value and repurchase intention. British Food Journal. 118 (12), 2963-2980. Available from: doi: 10.1108/BFJ-03-2016-0128

Wang, Q. J., Reinoso Carvalho, F., Persoone, D. \& Spence, C. (2017) Assessing the effect of shape on the evaluation of expected and actual chocolate flavour. Flavour. 6 (2), 1-6. Available from: doi: 10.1186/s13411-017-0052-1

Westerman, S. J., Sutherland, E. J., Gardner, P. H., Baig, N., Critchley, C., Hickey, C., Mehigan, S., Solway, A. \& Zervos, Z. (2013) The design of consumer packaging: Effects of manipulations of shape, orientation, and alignment of graphical forms on consumers' assessments. Food Quality and Preference. 27 (1), 8-17. Available from: doi: 10.1016/j.foodqual.2012.05.007

Wever, R., van Onselen, L., Silvester, S. \& Boks, C. (2010) Influence of packaging design on littering and waste behaviour. Packaging Technology and Science. 23 (5), 239-252. Available from: doi: 10.1002/pts.892

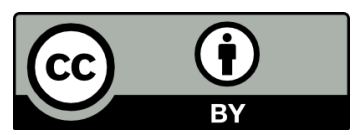

(C) 2021 Authors. Published by the University of Novi Sad, Faculty of Technical Sciences, Department of Graphic Engineering and Design. This article is an open access article distributed under the terms and conditions of the Creative Commons Attribution license 3.0 Serbia (http://creativecommons.org/licenses/by/3.0/rs/). 